\title{
Cello Pack
}

National Cancer Institute

\section{Source}

National Cancer Institute. Cello Pack. NCI Thesaurus. Code C43185.

A plastic 'clamshell' [thin plastic pre-formed structure for a device]. 